\title{
Bovine jugular vein valved conduit: Up to 10 years follow-up
}

\author{
Natasha Prior, MD, FRCS, ${ }^{\mathrm{a}}$ Nelson Alphonso, MD, FRCS, ${ }^{\mathrm{a}}$ Philip Arnold, BM, FRCA, ${ }^{\mathrm{b}}$ Ian Peart, MBChB, \\ FRCP, ${ }^{\mathrm{c}}$ Kent Thorburn, MMed, MRCP, FCPaed, FRCPCH, ${ }^{\mathrm{d}}$ Prem Venugopal, MCh, FRCS, ${ }^{\mathrm{a}}$ and \\ Antonio F. Corno, MD, FRCS, FACC, FETCS ${ }^{\mathrm{a}}$
}

Objective: The present study evaluated the mortality and conduit failure in bovine jugular vein (BJV) conduits.

Methods: Between October 1999 and February 2009, 193 patients (mean age, $6.7 \pm 5.8$ years; range, 5 days to 18 years; mean weight, $23.9 \pm 21.0 \mathrm{~kg}$; range, $2.4-105.4 \mathrm{~kg}$ ) had been discharged after BJV implantation. The reason for BJV implantation was right ventricular outflow tract reconstruction in 117 conduit replacement in 44, and the Ross procedure in 32. The diameter of the BJV was $12 \mathrm{~mm}$ in 18 patients $(9.3 \%), 14 \mathrm{~mm}$ in $16(8.3 \%)$, $16 \mathrm{~mm}$ in $42(21.7 \%), 18 \mathrm{~mm}$ in $37(19.2 \%), 20 \mathrm{~mm}$ in $15(7.8 \%)$, and $22 \mathrm{~mm}$ in $65(33.7 \%)$.

Results: At a mean \pm SD follow-up of $4.6 \pm 2.3 \mathrm{y}$ /patient (range, 8 months to 10 years), 5 late deaths $(2.6 \%)$ had occurred, all unrelated to conduit failure. Conduit-related problems required an interventional procedure as the first treatment in 10 patients $(5.2 \%)$ within a mean interval of $2.5 \pm 1.4$ years (range, 8 months to 5.3 years) or surgical revision in 5 patients $(2.6 \%)$ after $2.1 \pm 1.9$ years (range, 19 days to 4.1 years). Late deaths occurred in $5.9 \%(2 / 34)$ of patients with a BJV size of 12 to $14 \mathrm{~mm}$ versus $1.9 \%(3 / 159)$ in patients with a size of 16 to 22 $\mathrm{mm}(P=\mathrm{NS})$. An interventional procedure or surgical revision was required in $29.4 \%(10 / 34)$ of patients with a BJV size of 12 to $14 \mathrm{~mm}$ versus $3.1 \%(5 / 159)$ in patients with a size of 16 to $22 \mathrm{~mm}(P<.0005)$.

Conclusions: After 10 years of experience with the BJV, this conduit has remained a reliable alternative to pulmonary homografts with respect to survival and freedom from conduit failure. However, the incidence was greater and the presentation of conduit failure was earlier in patients with a smaller size BJV conduit (12-14 mm). (J Thorac Cardiovasc Surg 2011;141:983-987)

Earn CME credits at

http://cme.ctsnetjournals.org

The search for the ideal conduit to repair congenital heart defects has prompted investigation of various alternatives, including homografts; xenograft valves in Dacron, polytetrafluoroethylene, or pericardial conduits; stented and nonstented xenografts; and, more recently, tissue-engineered conduits. Pulmonary homografts, the conduit of choice in previous decades, have been limited by the smaller sizes, scarce availability, and potential for obstruction and calcification. ${ }^{1,2}$

The bovine jugular vein (BJV) (Contegra, Medtronic Inc, Minneapolis, Minn) was introduced into clinical practice as

\footnotetext{
From the Departments of Cardiac Surgery, ${ }^{\mathrm{a}}$ Anaesthesia, ${ }^{\mathrm{b}}$ Cardiology, ${ }^{\mathrm{c}}$ and Intensive Care, ${ }^{\mathrm{d}}$ Alder Hey Children National Health Service Foundation Trust, Liverpool, United Kingdom.

Disclosures: Authors have nothing to disclose with regard to commercial support. Received for publication March 15, 2010; revisions received June 30, 2010; accepted for publication Aug 1, 2010; available ahead of print Sept 30, 2010.

Address for reprints: Antonio F. Corno, MD, FRCS (Glasgow), FACC, FETCS, Chief, Pediatric Cardiac Surgery, Prince Salman Heart Center, King Fahad Medical City, PO Box 59046, Riyadh, 11525, Kingdom of Saudi Arabia (E-mail: acorno@kfmc. med.sa).

$0022-5223 / \$ 36.00$

Copyright $(C 2011$ Published by Elsevier Inc. on behalf of The American Association for Thoracic Surgery

doi:10.1016/j.jtcvs.2010.08.037
}

an alternative to the use of homografts in 1999 and has provided encouraging results in several reported clinical series. ${ }^{1,3-12}$

The recognized advantages of the BJV include the structural continuity between the wall of the jugular vein of the conduit and valve leaflets, which provides optimal hemodynamics because of the ideal effective orifice area; the unlimited "off-the-shelf" availability in sizes from 12 to $22 \mathrm{~mm}$ in diameter, representing a good alternative to the homograft shortage, particularly for the smaller sizes; the availability of a long length at both inflow and outflow that obviates the need for either proximal or distal augmentation and facilitating conduit tailoring and positioning that helps to avoid potential distortion and sternal compression; and exceptional reports of antigenic reaction because of glutaraldehyde fixation.

The main indication for this conduit remains right ventricular outflow tract reconstruction for complex congenital heart defects, either as an initial procedure requiring valved conduit implantation or at conduit replacement. After its successful introduction as the pulmonary valve replacement for the Ross operation, ${ }^{13}$ its use has also been expanded to this indication. $8,11,12,14$

In contrast to the good clinical results obtained from several institutions, ${ }^{3-11}$ a disturbing sequence of publications has reported stenosis at the level of the distal anastomosis of the conduit, with proximal conduit dilatation, aneurysm, or pseudoaneurysm, in $6 \%$ to $50 \%$ of patients. ${ }^{4-6,8,15-23}$ 


\section{Abbreviation and Acronym}

$\mathrm{BJV}=$ bovine jugular vein

In the present retrospective, single-center study, we evaluated the outcomes of BJV conduits during a follow-up of up to 10 years, with particular attention to late mortality and conduit failure requiring a surgical or catheter interventional procedure.

\section{MATERIALS AND METHODS}

The medical records of all patients in whom a BJV had been implanted were reviewed. Our institutional review board approved the study.

The data collection and analysis included the demographic data, diagnosis, previous interventional and surgical procedures, the indication for BJV implantation, the size of the implanted conduit, the duration of aortic crossclamping and cardiopulmonary bypass, the duration of the intensive care unit and hospital stay, the outcomes, including early (in-hospital or within 30 days after surgery) and late deaths, and all episodes of catheter intervention and/or surgery because of conduit failure. The point of conduit failure was defined as the interval between BJV implantation and the first required treatment. The choice between catheter intervention and surgery was decided by the interventional cardiologists and surgeons, taking into consideration the type of obstruction, such as a catheter procedure for patients with limited stenosis and conduit replacement for patients who were outgrowing the conduit.

Postoperatively, all patients had received intravenous heparin $(10 \mathrm{U} / \mathrm{kg} /$ h). This was transitioned before hospital discharge to antiplatelet treatment (aspirin at $3 \mathrm{mg} / \mathrm{kg} / \mathrm{d}$ ) for 1 year.

All patients were followed with clinical examination and serial transthoracic echocardiography every 6 to 12 months until October 2009 .

\section{Statistical Analysis}

Continuous variables were calculated as the mean \pm standard deviation. Comparative analyses were performed using paired Student's $t$ and $\chi^{2}$ tests. Patient survival and freedom from conduit failure were determined using the Kaplan-Meier method and the Wilcoxon test.

\section{RESULTS}

\section{Demographic Data}

Between October 1999 and February 2009, 198 patients had undergone BJV implantation.

The surgical indications included right ventricular outflow tract reconstruction in 120 patients, conduit replacement in 46, and the Ross procedure in 32 .

For the purposes of the present study, we excluded from the data analysis, all patients with an early death $(\mathrm{n}=5)$, all of which were unrelated to the conduit.

The study population therefore included 193 patients, 109 males $(56.5 \%)$ and 84 females $(43.5 \%)$, with a mean age of $6.7 \pm 5.8$ years (range, 5 days to 18 years) and mean weight of $23.9 \pm 21.0 \mathrm{~kg}$ (range, 2.4 to $105.4 \mathrm{~kg}$ ) at BJV implantation.

The specific diagnosis for each group is listed in Table 1.

Of the 193 patients, $138(71.5 \%)$ had previously undergone surgery, for a total of 158 procedures, including 44
TABLE 1. Distribution of diagnosis

\begin{tabular}{|c|c|c|}
\hline Indication & Diagnosis & Patients (n) \\
\hline \multirow[t]{12}{*}{ RVOT reconstruction } & & 117 \\
\hline & Tetralogy of Fallot & 28 \\
\hline & Absent PV & 5 \\
\hline & Complete AVSD & 5 \\
\hline & $\mathrm{PA}, \mathrm{VSD}$ & 28 \\
\hline & PV regurgitation after & 21 \\
\hline & TF repair & \\
\hline & TGA, VSD, PS/PA & 16 \\
\hline & Truncus arteriosus & 13 \\
\hline & Aortic arch interruption & 1 \\
\hline & DORV, VSD, PS & 9 \\
\hline & PA, IVS & 2 \\
\hline \multirow[t]{7}{*}{ Conduit replacement } & & 44 \\
\hline & $\mathrm{PA}, \mathrm{VSD}$ & 14 \\
\hline & Tetralogy of Fallot & 12 \\
\hline & Absent PV & 1 \\
\hline & Truncus arteriosus & 12 \\
\hline & TGA, VSD, PS/PA & 5 \\
\hline & DORV, VSD, PS & 1 \\
\hline \multirow[t]{4}{*}{ Ross procedure } & & 32 \\
\hline & Aortic valve stenosis & 13 \\
\hline & Aortic valve regurgitation & 12 \\
\hline & $\begin{array}{l}\text { Aortic valve stenosis/ } \\
\text { regurgitation }\end{array}$ & 7 \\
\hline
\end{tabular}

RVOT, Right ventricular outflow tract; $P V$, pulmonary valve; $A V S D$, atrioventricular septal defect; $P A$, pulmonary atresia; $V S D$, ventricular septal defect; $T F$, tetralogy of Fallot; TGA, transposition of great arteries; PS, pulmonary stenosis; DORV, double-outlet right ventricle; IVS, intact ventricular septum.

patients who had undergone previous conduit implantation (Table 2).

The diameter of the implanted BJV, decided by the surgeon on the basis of the expected size of the pulmonary artery for the patient's age and body weight, was $12 \mathrm{~mm}$ for 18 patients $(9.3 \%), 14 \mathrm{~mm}$ in $16(8.3 \%), 16 \mathrm{~mm}$ in $42(21.7 \%), 18 \mathrm{~mm}$ in $37(19.2 \%), 20 \mathrm{~mm}$ in $15(7.8 \%)$, and $22 \mathrm{~mm}$ in 65 patients $(33.7 \%)$.

\section{Late Mortality}

At a mean follow-up period of $4.6 \pm 2.3 \mathrm{y} /$ patient (range, 8 months to 10 years), 5 late deaths $(2.6 \%)$ had occurred, all unrelated to conduit failure. Of the 5 patients who died, 4 had had right ventricular outflow tract reconstruction $(4 / 117=3.4 \%)$. The diagnosis was truncus arteriosus in 1 patient; pulmonary valve regurgitation after repair of tetralogy of Fallot in 1 patient; double-outlet right ventricle with ventricular septal defect and pulmonary stenosis in 1 patient; and, in the last patient, transposition of the great arteries with ventricular septal defect and pulmonary stenosis. The fifth patient died after conduit replacement $(1 / 44=2.3 \%)$. No late deaths occurred in the group of patients undergoing a Ross procedure. The overall survival rate at 10 years was $96 \%$ (Figure 1). Late deaths in relation to the surgical indication are summarized in Table 3. 
TABLE 2. Previous procedures

\begin{tabular}{|c|c|c|}
\hline Procedure & Specification & Patients (n) \\
\hline \multirow{7}{*}{ Systemic-pulmonary shunt } & & 71 \\
\hline & Modified Blalock-Taussig & 59 \\
\hline & Right & 42 \\
\hline & Bilateral & 9 \\
\hline & Left & 8 \\
\hline & Central shunt & 10 \\
\hline & Waterston & 2 \\
\hline \multirow[t]{5}{*}{ Conduit replacement } & & 44 \\
\hline & Homograft & 40 \\
\hline & Shellhigh & 2 \\
\hline & Contegra (infection) & 1 \\
\hline & Biocore & 1 \\
\hline \multirow[t]{7}{*}{ Aortic valve procedure } & & 22 \\
\hline & Balloon dilation & 17 \\
\hline & $2 \times$ & 1 \\
\hline & $3 \times$ & 2 \\
\hline & $4 \times$ & 1 \\
\hline & Open valvotomy & 4 \\
\hline & Valve repair + VSD closure & 1 \\
\hline \multirow[t]{2}{*}{ RVOT enlargement } & & 5 \\
\hline & With VSD closure & 3 \\
\hline Pulmonary artery banding & & 4 \\
\hline Aortic coarctectomy & & 4 \\
\hline Aortic arch repair + D-K-S & & 3 \\
\hline Pacemaker implantation & & 2 \\
\hline Norwood/Sano & & 1 \\
\hline Arterial switch & & 1 \\
\hline Subaortic resection & & 1 \\
\hline
\end{tabular}

$\overline{V S D}$, Ventricular septal defect; $R V O T$, right ventricular outflow tract; $D-K-S$, DamusKaye-Stansel procedure.

\section{Conduit Failure}

Conduit-related problems necessitated an interventional procedure as the first treatment in 10 patients $(5.2 \%)$ within a mean interval of $2.5 \pm 1.4$ years (range, 8 months to 5.3 years) and surgical revision in 5 patients $(2.6 \%)$ after $2.1 \pm 1.9$ years (range, 19 days to 4.1 years)

Of the 10 patients requiring a catheter-based intervention as the first treatment of conduit failure, $3(30 \%)$ required a second catheter intervention after 4,12 , and 30 months

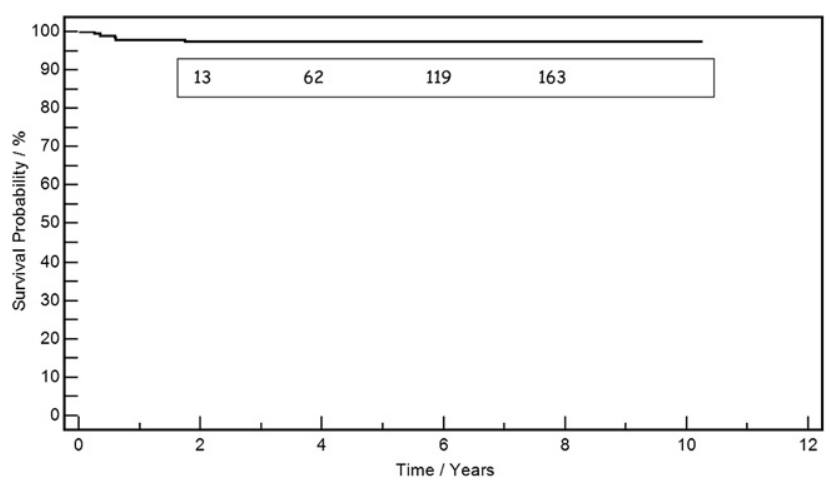

FIGURE 1. Overall survival. Total number of patients enrolled during follow-up, excluding late deaths, indicated every 2 years.
TABLE 3. Late mortality and conduit failure in relation to surgical indication

\begin{tabular}{lccr}
\hline \multicolumn{1}{c}{ Indication } & Patients (n) & $\begin{array}{c}\text { Late } \\
\text { death }(\mathbf{n})\end{array}$ & $\begin{array}{c}\text { Conduit } \\
\text { failure (n) }\end{array}$ \\
\hline RVOT reconstruction & 117 & $4(3.4 \%)$ & $10(8.5 \%)$ \\
Conduit replacement & 44 & $1(2.3 \%)$ & $4(9.1 \%)$ \\
Ross procedure & 32 & $0(0 \%)$ & $1(3.1 \%)$ \\
\hline
\end{tabular}

RVOT, Right ventricular outflow tract.

(followed by surgery in 1 ) and $2(20 \%)$ required surgery as the subsequent treatment after 24 and 45 months. The remaining 5 patients undergoing a catheter-based intervention had not required any additional treatment after a mean interval of $35 \pm 17$ months (range, 17 to 58 months).

Conduit failure had resulted from obstruction in $14(93 \%)$ and valve regurgitation in $1(7 \%)$ of 15 patients and was never because of BJV calcification, even in the smaller size conduits. The overall freedom from conduit failure rate at 10 years was $90 \%$ (Figure 2). The conduit failure data are summarized in Table 3 stratified by the surgical indication.

\section{Conduit Size}

Late deaths occurred in $5.9 \%(2 / 34)$ of the patients with a BJV size of 12 to $14 \mathrm{~mm}$ versus $1.9 \%$ (3/159) of the patients with a size of 16 to $22 \mathrm{~mm}(P=\mathrm{NS})$.

Catheter intervention or surgical revision was required in $10(29.4 \%)$ of 34 patients with a BJV conduit of 12 to $14 \mathrm{~mm}$ versus $5(3.1 \%)$ of 159 patients with 16 to $22 \mathrm{~mm}$ $(P<.0005)$.

The late deaths and conduit failures in relation to BJV size are summarized in Table 4, and the statistical analysis results of the late mortality and conduit failure in relation to the BJV conduit size are summarized in Table 5.

Kaplan-Meier curves showing the survival and successful use of a BJV conduit (ie, freedom from intervention) are reported in Figures 3 and 4, respectively.

An infant who had developed conduit endocarditis 9 months after BJV implantation for pulmonary atresia with ventricular septal defect required conduit replacement.

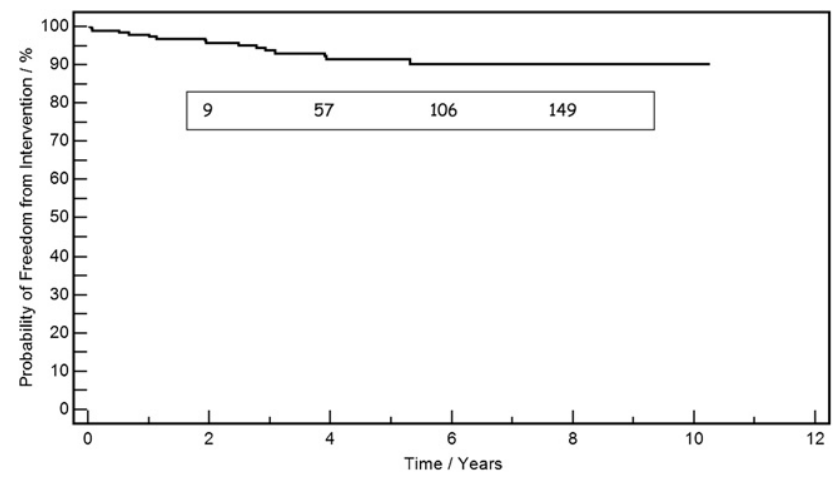

FIGURE 2. Overall freedom from intervention. Total number of patients enrolled in during follow-up, excluding late deaths and patients who underwent intervention, indicated every 2 years. 
TABLE 4. Late mortality and conduit failure in relation to BJV conduit size

\begin{tabular}{lccc}
\hline Size $(\mathbf{m m})$ & Patients $(\mathbf{n})$ & Late death $(\mathbf{n})$ & Conduit failure $(\mathbf{n})$ \\
\hline 12 & 18 & $1(5.6 \%)$ & $5(27.8 \%)$ \\
14 & 16 & $1(6.3 \%)$ & $5(31.3 \%)$ \\
16 & 42 & $0(0 \%)$ & $2(4.8 \%)$ \\
18 & 37 & $2(5.4 \%)$ & $1(2.7 \%)$ \\
20 & 15 & $0(0 \%)$ & $1(6.7 \%)$ \\
22 & 65 & $1(1.5 \%)$ & $1(1.5 \%)$ \\
\hline
\end{tabular}

Although the reoperation was related to the conduit, this patient was not included in the primary conduit failure group because the reason for reoperation was infection rather than hemodynamic deterioration.

\section{DISCUSSION}

The present 10-year study evaluated the long-term outcomes after BJV implantation, with particular attention to survival and conduit durability, defined as freedom from an interventional procedure or surgery required for conduit failure.

Our clinical experience with the BJV is the largest reported single-center series of patients with up to 10 years of follow-up. Our results have confirmed the good results reported by other smaller series ${ }^{3-11}$ with respect to survival and freedom from conduit failure, with an overall survival rate greater than $96 \%$ at 10 years (Figure 1) and an overall freedom from conduit failure rate greater than $90 \%$ at 10 years (Figure 2 ).

No difference was seen in survival or the freedom from conduit failure between the first implantation for right ventricular outflow tract reconstruction and conduit replacement. The BJV provided very good results in the Ross procedure, with no late mortality and only 1 patient requiring conduit replacement 4 years after a neonatal Ross procedure.

The significantly greater incidence $(29.4 \%$ vs $3.1 \%$, $P<.0005)$ of conduit failure observed with the smaller (12 and $14 \mathrm{~mm}$ ) compared with the larger (16 to $22 \mathrm{~mm}$ ) BJV conduits was directly related to the patients' age and body weight

TABLE 5. Statistical analysis of late mortality and conduit failure in relation to $\mathrm{BJV}$ conduit size

\begin{tabular}{lccc}
\hline & \multicolumn{2}{c}{ Size $(\mathbf{m m})$} & \\
\cline { 2 - 3 } \multicolumn{1}{c}{ Variable } & $\mathbf{1 2 - 1 4}$ & $\mathbf{1 6 - 2 2}$ & $\boldsymbol{P}$ value \\
\hline Patients & 34 & 159 & $<.0001$ \\
Age (y) & 1.2 & 7.8 & \\
$\quad$ Mean & $3 \mathrm{~d}$ to $8.9 \mathrm{y}$ & $22 \mathrm{~d}$ to $17.9 \mathrm{y}$ & \\
$\quad$ Range & 6.9 & & \\
Weight $(\mathrm{kg})$ & $2.4-38.9$ & 27.5 & \\
$\quad$ Mean & $2(5.9 \%)$ & $2.7-105.4$ & $\mathrm{NS}$ \\
$\quad$ Range & $10(29.4 \%)$ & $3(1.9 \%)$ & $<.0005$ \\
Late death & $5(3.1 \%)$ & \\
Conduit failure & & & \\
\hline
\end{tabular}

$B J V$, Bovine jugular vein; $N S$, not statistically significant.

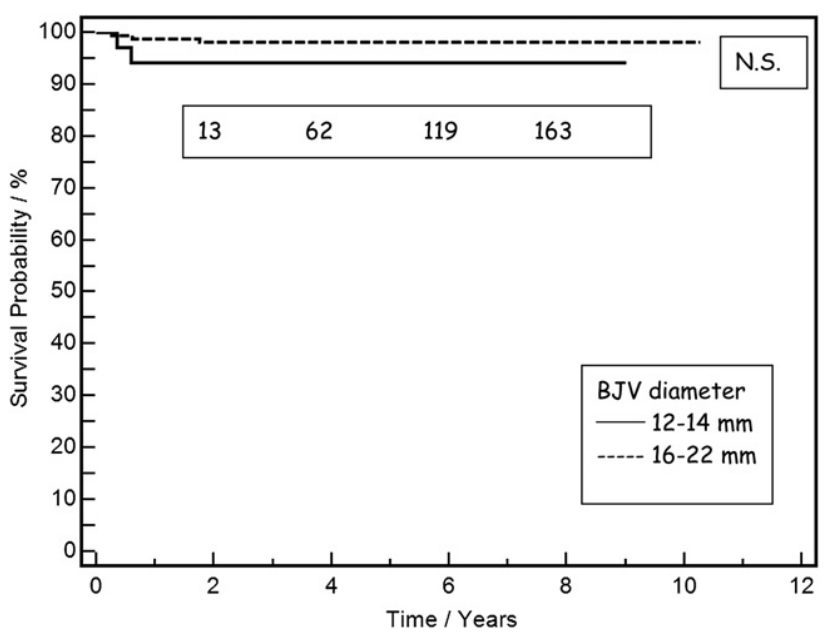

FIGURE 3. Survival comparing different sizes of bovine jugular vein $(B J V): 12$ to $14 \mathrm{~mm}$ versus 16 to $22 \mathrm{~mm}$. Total number of patients enrolled during follow-up, excluding late deaths, indicated every 2 years.

at implantation (Table 4). This conduit failure resulted from the patient outgrowing the conduit. This has been a recurrent problem observed in small patients, independent of the type of biologic valved conduit used, because a difficult balance must be reached among the need to limit the size of the ventriculotomy, the space available in the mediastinum, and the instinct to implant the largest possible conduit. $1,2,6,16$

The problem of conduit dilatation related to obstruction at the distal anastomosis has been reported as a specific complication of BJV conduits. ${ }^{15-23}$ The following mechanisms have been recognized as potential causes of distal stenosis: the presence of hypoplasia and/or distal stenosis of the pulmonary artery branches; a discrepancy in the size between the conduit and pulmonary artery; the surgical technique used; a local immunologic/inflammatory reaction;

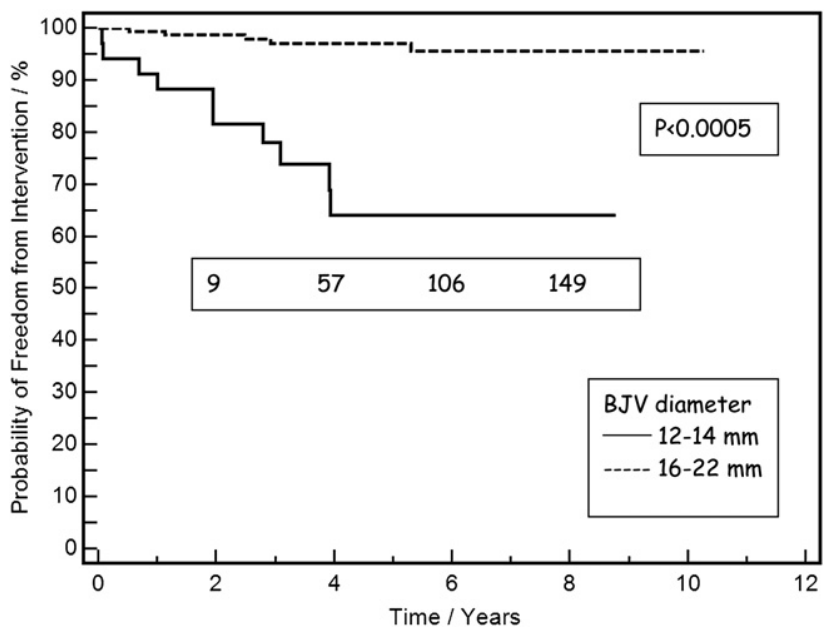

FIGURE 4. Freedom from intervention stratified by bovine jugular vein (BJV) size: 12 to $14 \mathrm{~mm}$ versus 16 to $22 \mathrm{~mm}$. Total number of patients enrolled during follow-up, excluding late deaths and patients who underwent intervention, indicated every 2 years. 
local peel formation; thrombosis; and a combination of 2 or more of these factors. ${ }^{24}$

The effect of the surgical technique has been previously studied using computational fluid dynamics to compare 2 types of distal anastomosis: the conventional end-to-end "circular" anastomosis versus the oblique "elliptical" anastomosis, with the incision extended on to the anterior aspect of the left pulmonary artery and the distal end of the conduit obliquely tailored. That study confirmed a larger cross-sectional area in the "elliptical" compared with the "circular" type of anastomosis, along with a more homogeneous velocity, pressure, and shear stress distribution. ${ }^{24}$ These results suggested that the "elliptical" anastomosis might reduce the incidence and degree of distal stenosis, particularly for smaller conduits. Therefore, we adopted this technique for the distal anastomosis, in addition to careful rinsing ( 5 minutes, three times, in different saline solutions) before implantation to clear the glutaraldehyde and reduce the inflammatory reaction and avoidance of oversize conduits to reduce the discrepancy between the conduit and distal pulmonary artery size. Using this protocol, distal conduit stenosis has become a rare complication in our experience, even with the smaller conduits.

Early calcification of biologic valved conduits has been frequently reported with homografts, particularly in infants or small children in the first few years of age. ${ }^{1,2}$ In the present study, early conduit calcification causing hemodynamic consequences was never observed, confirming our own previous observations and those of other investigators. ${ }^{4-6,8}$

Despite the encouraging results of our study, we recognize the need to continue to investigate alternative surgical options, such as the valveless conduit and the monocusp transannular patch, to minimize the use of valved conduits in small infants. These surgical approaches would delay reoperation, making implantation of a larger size BJV conduit more feasible.

\section{CONCLUSIONS}

After 10 years of experience with BJV, this conduit has remained a reliable alternative to pulmonary homografts, which are still considered the first choice when a biologic valved conduit is required. The incidence of conduit failure was greater and the presentation was earlier in patients with a smaller size BJV (12-14 mm). Alternative surgical approaches should be investigated to avoid the use of smaller size conduits in small infants.

We are grateful to Dr. Tom Karl, Brisbane, Australia, for his review of the manuscript and helpful comments.

\section{References}

1. Karamlou T, Blackstone EH, Hawkins JA, Jacobs ML, Kanter KR, Brown JW, et al. Can pulmonary conduit dysfunction and failure be reduced in infants and children less than age 2 years at initial implantation? J Thorac Cardiovasc Surg. 2006;132:829-38.
2. Wells WJ, Arroyo H, Bremner RM, Wood J, Starnes VA. Homograft conduit failure in infants is not due to somatic outgrowth. J Thorac Cardiovasc Surg. 2002; 24:88-96.

3. Bove T, Demanet H, Wauthy P, Goldstein JP, Dessy H, Viart P, et al. Early results of valved bovine jugular vein conduit versus bicuspid homograft for right ventricular outflow tract reconstruction. Ann Thorac Surg. 2002;74:536-41.

4. Breymann T, Thies WR, Boething D, Goerg R, Blanz U, Koerfer R. Bovine valved venous xenografts for RVOT reconstruction: Results after 71 implantations. Eur J Cardiothorac Surg. 2002;21:703-10.

5. Breymann T, Blanz U, Woitalik MA, Daenen W, Hetzer R, Sarris G, et al. European Contegra multicentre study: 7-Year results after 165 valved bovine jugular vein graft implantations. Thorac Cardiovasc Surg. 2009;57:257-69.

6. Brown JW, Ruzmetov M, Rodefeld MD, Vijay P, Darragh RK. Valved bovine jugular vein conduits for right ventricular outflow tract reconstruction in children: An attractive alternative to pulmonary homograft. Ann Thorac Surg. 2006;82:909-16

7. Carrel T, Berdat P, Pavlovic M, Pfammatter JP. The bovine jugular vein: A totally integrated valved conduit to repair the right ventricular outflow. J Heart Valve Dis. 2002;11:552-6.

8. Corno AF, Qanadli SD, Sekarski N, Artemisia S, Hurni M, Tozzi P, et al. Bovine valved xenograft in pulmonary position: Medium-term follow-up with excellent hemodynamics and freedom from calcifications. Ann Thorac Surg. 2004;78: 1382-8.

9. Hickey ED, McCrindle BW, Blackstone EH, Yeh T, Pigula F, Clarke D, et al Jugular venous conduit (Contegra) matches allograft performance in infant truncus arteriosus repair. Eur J Cardiothorac Surg. 2008;33:890-8.

10. Raja SG, Rasool F, Yousuffudin S, Danton MD, MacArthur KJ, Pollock JC. Current status of the Contegra conduit for pediatric right ventricular outflow tract reconstruction. J Heart Valve Dis. 2005;14:616-22.

11. Sekarski N, van Meir H, Rijlaarsdam MEB, Schoof PH, Koolbergen DR, Hruda J, et al. Right ventricular outflow tract reconstruction with the bovine jugular vein graft: 5 Years' experience with 133 patients. Ann Thorac Surg. 2007;84:599-605.

12. Tiete AR, Sachweh JS, Roemer U, Kozlik-Feldmann R, Reichart B, Daebritz SH. Right ventricular outflow tract reconstruction with the Contegra bovine jugular vein conduit: A word of caution. Ann Thorac Surg. 2004;77:2151-6.

13. Corno AF, Hurni M, Griffin H, Jeanrenaud X, von Segesser LK. Glutaraldehydefixed bovine jugular vein as a substitute for the pulmonary valve in the Ross operation. J Thorac Cardiovasc Surg. 2001;122:493-4.

14. Purohit M, Kitchiner D, Pozzi M. Contegra bovine jugular vein right ventricle to pulmonary artery conduit in Ross procedure. Ann Thorac Surg. 2004;77:1707-10

15. Bautista-Hernandez V, Kaza AK, Benavidez OJ, Pigula FA. True aneurysmal dilatation of a Contegra conduit after right ventricular outflow tract reconstruction: A novel mechanism of conduit failure. Ann Thorac Surg. 2008;86:1976-7.

16. Boethig D, Thies WR, Hecker H, Breymann T. Mid term course after pediatric right ventricular outflow tract reconstruction: A comparison of homografts, porcine xenografts and Contegra. Eur J Cardiothorac Surg. 2005;27:58-66.

17. Boudjemline Y, Bonnet D, Agnoletti G, Vouhé P. Aneurysm of the right ventricular outflow following bovine valved venous conduit insertion. Eur J Cardiothorac Surg. 2003;23:122-4.

18. Göber V, Berdat P, Pavlovic M, Pfammatter JP, Carrel TP. Adverse mid-term outcome following RVOT reconstruction using the Contegra valved bovine jugular vein. Ann Thorac Surg. 2005;79:625-31.

19. Kadner A, Dave H, Stallmach T, Turina M, Prêtre R. Formation of a stenotic fibrotic membrane at the distal anastomosis of bovine jugular vein grafts (Contegra) after right ventricular outflow tract reconstruction. $J$ Thorac Cardiovasc Surg. 2004;127:285-6.

20. Meyns B, van Garsse L, Boshoff D, Eyskens B, Mertens L, Gewillig M, et al. The Contegra conduit in the right ventricular outflow tract induces supravalvular stenosis. J Thorac Cardiovasc Surg. 2004;128:834-40.

21. Morales DL, Braud BE, Gunter KS, Carberry KE, Arrington KA, Heinle JS, et al. Encouraging results for the Contegra conduit in the problematic right ventricleto-pulmonary artery connection. J Thorac Cardiovasc Surg. 2006;132:665-71.

22. Rastan AJ, Walther T, Daehnert I, Hambsch J, Mohr FW, Janousek J, et al. Bovine jugular vein conduit for right ventricular outflow tract reconstruction: Evaluation of risk factors for mid-term outcome. Ann Thorac Surg. 2006;82:1308-15.

23. Shebani SO, McGuirk S, Baghai M, Stickley J, De Giovanni JV, Bu'lock FA, et al. Right ventricular outflow tract reconstruction using Contegra valved conduit: Natural history and conduit performance under pressure. Eur J Cardiothorac Surg. 2006;29:397-405.

24. Corno AF, Mickaily-Huber ES. Comparative computational fluid dynamic study of two distal Contegra conduit anastomoses. Int Cardiovasc Thorac Surg. 2008;7:1-5. 